\title{
(ters) Environmental Stress Testing of Wafer-Level Au-Au
Thermocompression Bonds Realized at Low Temperature:
Strength and Hermeticity
}

\author{
N. Malik, ${ }^{a, b, *, z}$ H. R. Tofteberg, ${ }^{\text {b }}$ E. Poppe, ${ }^{\text {b }}$ T. G. Finstad, ${ }^{a}$ and K. Schjølberg-Henriksen ${ }^{\mathrm{b}, * *}$ \\ ${ }^{a}$ Centre for Materials Science and Nanotechnology, University of Oslo, Oslo, Norway \\ ${ }^{b}$ SINTEF ICT, Department of Microsystems and Nanotechnology, N-0314 Oslo, Norway
}

Hermeticity, reliability and strength of four laminates bonded at different temperatures by Au-Au thermocompression bonding have been investigated. Laminates with a diameter of $150 \mathrm{~mm}$ were realized by bonding a wafer containing membrane structures to a $\mathrm{Si}$ wafer with patterned bond frames. A bond tool pressure of $2266 \mathrm{mbar}$ was applied for 15 minutes at temperatures ranging from $150-300^{\circ} \mathrm{C}$. The hermetic properties were estimated by membrane deflection measurements applying white-light interferometry after bonding. Reliability was tested by exposing the laminates to a steady-state life test, a thermal shock test, and a moisture resistance test. Bond strength was estimated by pull test measurements. A dicing yield above $90 \%$ was obtained for all laminates. Laminates bonded at $200^{\circ} \mathrm{C}$ and above had significantly higher hermetic yield than the laminate bonded at $150^{\circ} \mathrm{C}$. No degradation in hermeticity was observed after the reliability tests. The maximum leakage rate (MLR) was estimated from two measurements of membrane deflection executed at two different times and was below $10^{-11} \mathrm{mbar} \cdot 1 \cdot \mathrm{s}^{-1}$. The average bond strength ranged from 44 to $175 \mathrm{MPa}$. (C) The Author(s) 2015. Published by ECS. This is an open access article distributed under the terms of the Creative Commons Attribution 4.0 License (CC BY, http://creativecommons.org/licenses/by/4.0/), which permits unrestricted reuse of the work in any medium, provided the original work is properly cited. [DOI: 10.1149/2.0201507jss] All rights reserved.

Manuscript submitted February 6, 2015; revised manuscript received April 22, 2015. Published April 29, 2015. This was Paper 1736 presented at the Cancun, Mexico, Meeting of the Society, October 5-9, 2014.

Micro electro mechanical systems (MEMS) devices, especially inertial sensors, such as mechanical resonators, gyroscopes and accelerometers, can have fragile parts which need to be sealed in a high vacuum environment for high performance and long life time. A controlled ambient pressure is required in many of these devices because of their mechanical damping characteristics. MEMS absolute pressure sensors require a vacuum cavity as a zero pressure reference. Therefore, hermetic packaging is an essential requirement for such environment sensitive MEMS devices. ${ }^{1}$

Metal thermocompression bonding is a promising technology for hermetic encapsulation of MEMS devices. Metals do not only provide hermetic seals for a longer duration than polymers and glasses but also enable significant reduction in die size because of smaller seal frames. ${ }^{2}$ Fraux and Baron ${ }^{3}$ reported that STMicroelectronics obtained die shrinkage of $57 \%$ by replacing the glass-frit bonding by $\mathrm{Au}-\mathrm{Au}$ thermocompression bonding. $\mathrm{Au}$ is a promising metal for thermocompression bonding with a number of advantages: $\mathrm{Au}$ is a biocompatible material and can be used in harsh environments. There is no native oxide formed on the surface of $\mathrm{Au}$, while on the surface of $\mathrm{Cu}$ and $\mathrm{Al}$, a native oxide is formed. ${ }^{4}$ The absence of oxide enables direct contact between two opposing metals. The direct contact probably facilitates the formation of bonds between two metal bodies, and may allow bonding to be performed with lower pressure and/or at a lower temperature. Successful Au-Au thermocompression bonding has been reported ${ }^{5-7}$ in the temperature range 260 to $350^{\circ} \mathrm{C}$. A low bonding temperature bonding is generally desired in order to reduce the thermomechanically induced stress in the bonded devices. Bonding of sputter deposited Au films has been reported at temperatures as low as $100^{\circ} \mathrm{C} .{ }^{8}$ Bonding of porous Au has been performed at room temperature. ${ }^{9}$ To our knowledge, reports on the reliability and hermeticity of $\mathrm{Au}-\mathrm{Au}$ thermocompression bonds have not yet been presented.

Hermeticity testing is commonly done in accordance with MILSTD-883 test methods. However, the rejection leak rates mentioned in MIL-STD-883 are not valid for package volumes below $0.05 \mathrm{~cm}^{3} .^{10}$ More stringent rejection rates for volumes below $0.01 \mathrm{~cm}^{3}$ are given in MIL-STD-750E. Traditionally, leak rates were determined by gross bubble test along with He "fine leak" test (range $10^{-4}$ to $10^{-10}$ atm $\mathrm{cc} / \mathrm{sec}$ ). Now, depending on the application, more sensitive and accurate leak rate testing methods are available. Optical measurement

\footnotetext{
*Electrochemical Society Student Member.

**Electrochemical Society Active Member.

${ }^{\text {z} E-m a i l: ~ n i s h a n t . m a l i k @ s m n . u i o . n o ; ~ n i s h a n t m a l i k 1987 @ g m a i l . c o m ~}$
}

of changes in membrane deflection, Fourier transform infrared spectroscopy (FTIR), Q-factor testing and residual gas analysis are some of the leak rate tests methods. ${ }^{11}$ The helium leak rate of Au-Au thermocompression bonds was reported to be $2.74 \times 10^{-10} \mathrm{mbar} \cdot 1 \cdot \mathrm{s}^{-1}$ by Park et al. ${ }^{12}$ and $3.9 \times 10^{-9} \mathrm{mbar} \cdot 1 \cdot \mathrm{s}^{-1}$ by Xu et al. ${ }^{13}$

Reliability is a key factor of industrial MEMS devices. Various standardized test procedures that are relevant for different device specifications are available. MIL-STD-883 is one such standardized procedure, containing a list of exposure conditions and tests. In order to test the reliability of a bonded seal, a sub-set of exposure conditions is chosen. Even if the seal itself passes a specific exposure condition, it is possible that other properties of a functioning MEMS device is adversely affected by that specific exposure condition, so that the packaged device fails the reliability test even if the seal alone did pass the test.

This paper presents the effects of environmental stress on the bond strength and hermeticity of Au-Au thermocompression bonds. The initial screening of the die seals was done by optically measuring membrane deflection after bonding. To check the reliability of the bonded seals, changes in membrane deflection following steady-state life, thermal shock and moisture resistance tests were measured. A maximum leak rate (MLR) was also estimated by measuring the membrane deflection at two different times. The bond strength was investigated by counting the dicing yield of laminates and by pull test measurements on individual dies.

\section{Experimental}

Wafer design. - The top Si wafers $(150 \mathrm{~mm})$ had cavities with pressure-sensitive membranes. The cavities were sealed with bottom $\mathrm{Si}$ wafers consisting of bond frames of different widths. The cavity wafers had 481 membrane structures with nominal thickness $41 \mu \mathrm{m}$ and nominal side edges of $2.5 \mathrm{~mm} \times 2.5 \mathrm{~mm}$. The membranes of sealed cavities deflected after bonding. The relationship between the membrane deflection and the pressure difference between the inside and outside of the sealed cavity is given by the following equation. ${ }^{14}$ The addition of $750 \mathrm{~nm} \mathrm{SiO} 2$ on top of the $\mathrm{Si}$ membrane will make the membrane stiffer; hence the deflection $w$ will be slightly reduced. However, since the thickness of the $\mathrm{SiO}_{2}$ layer was $1 / 50$ of the thickness of the Si membrane, its effect on the membrane deflection was neglected in the calculation.

$$
w=\left(a^{4 *}\left(1-v^{2}\right)^{*} \Delta P\right) /\left(66^{*} d^{3 *} E\right)
$$




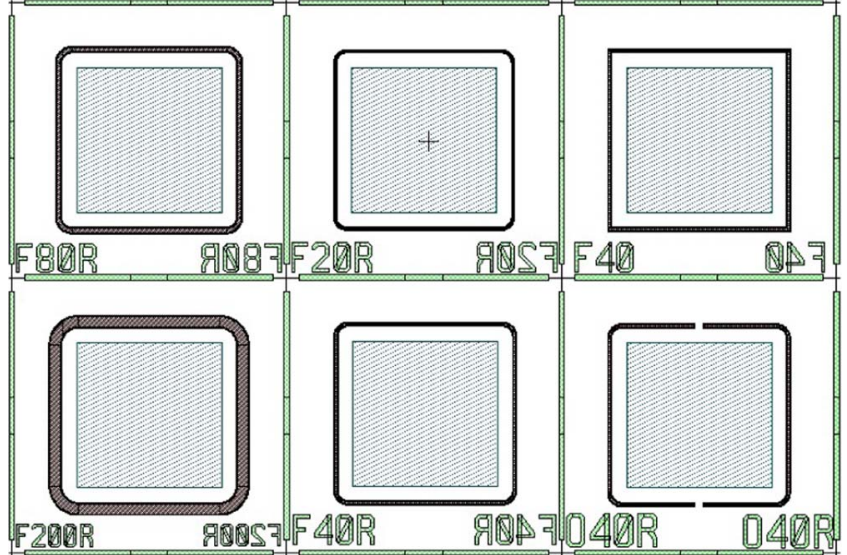

Figure 1. Mask layout for the six frame designs. In the lower left corner of each die there is a key describing the design: " $\mathrm{F}$ " is for Frame, "O" is for Open frame, " 80 " is for $80 \mu \mathrm{m}$ nominal width of the frame, and " $\mathrm{R}$ " is for Rounded corner.

Here, $w$ is the deflection, $a$ is the membrane side length, $d$ is the membrane thickness, $v$ is the Poisson's ratio, $E$ is the Young's modulus, and $\Delta P$ is the pressure difference.

The bottom wafer had Au frame structures of width 20,40, 80 and $200 \mu \mathrm{m}$, which defined the bonding area. All frame designs had rounded corners, but a version with square corners was added with a $40 \mu \mathrm{m}$ wide frame for comparing square corner design with rounded corner design, see Figure 1. Also one design of each frame width having a $200 \mu \mathrm{m}$ long gap in the frame structure at two different positions was added in order to have a few intentionally unsealed cavities for reference purposes. All frame structures had inner dimensions of $3.34 \mathrm{~mm} \times 3.34 \mathrm{~mm}$. The various designs were distributed evenly across the wafer. The Au bond frame was unintentionally over-etched on all bottom wafers. This resulted in bond frames which were all 10 $\mu \mathrm{m}$ narrower than designed. The total bonding area of all bond frames on a $150 \mathrm{~mm}$ wafer was $504 \mathrm{~mm}^{2}$. The frame types, the number of dies of each frame type and their actual widths and bond areas are listed in Table I. To allow for a certain misalignment during bonding, the $\mathrm{Au}$ frames patterned on the top wafers were $40 \mu \mathrm{m}$ wider than their corresponding protruding bond frame structure on the bottom wafers. Figure 2 shows a schematic cross-section of a bonded die.

Laminate preparation. - Four laminates were prepared. The top $\mathrm{Si}$ wafers contained membrane structures and the bottom $\mathrm{Si}$ wafers contained frame structures. The thickness of the top wafers was $280 \mu \mathrm{m}$. The membranes in the top wafers were made using tetramethyl ammonium hydroxide (TMAH) etching. A thermal $\mathrm{SiO}_{2}$ of $750 \mathrm{~nm}$ was used as masking material and the mask was not removed after the etching. The corresponding layer of $\mathrm{SiO}_{2}$ on the front side of the wafer was patterned to write the die ID. The membranes were fully covered by $\mathrm{SiO}_{2}$ on the front side. The bottom wafers were $400 \mu \mathrm{m}$ thick with a $150 \mathrm{~nm}$ thick thermal $\mathrm{SiO}_{2}$ layer. Before bonding, layers of $400 \mathrm{~nm}$ thick TiW and $1.2 \mu \mathrm{m}$ thick Au were sputter deposited on all top and bottom wafers. The Au and TiW layers were patterned by wet etching on the top wafers and bottom wafers. The TiW was $50 \mu \mathrm{m}$

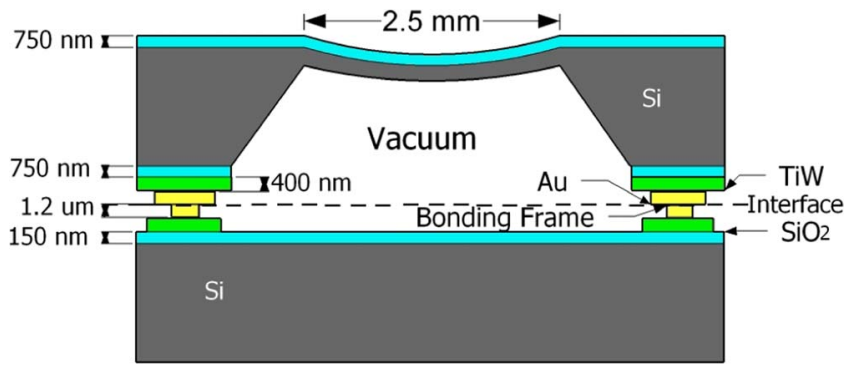

Figure 2. Schematic cross-section of a bonded die. The top wafers contained membrane structures.

Table II. Overview of laminate types and bond parameters.

Laminate ID $\quad$ Tool pressure (mbar) $\quad$ Temperature $\left({ }^{\circ} \mathrm{C}\right) \quad$ Time (minutes)

$\begin{array}{llll}\text { Au150 } & 2266 & 150 & 15 \\ \text { Au200 } & 2266 & 200 & 15 \\ \text { Au250 } & 2266 & 250 & 15 \\ \text { Au300 } & 2266 & 300 & 15\end{array}$

wider than $\mathrm{Au}$ on the top wafer and $20 \mu \mathrm{m}$ wider on the bottom wafer to avoid any direct contact between $\mathrm{Au}$ and $\mathrm{Si}$ and the subsequent formation of AuSi eutectic upon heating of the wafer stack.

Bonding. - The wafers were aligned and then bonded in an SB6e (Suss MicroTec) wafer bonder. The wafers were separated by spacers in the bonder after alignment. The ambient pressure in the bonding chamber was reduced to below $5 \times 10^{-3}$ mbar before the spacers were removed. The thermocompression bonding was performed by applying a tool pressure of $2266 \mathrm{mbar}$ (bond force of $5 \mathrm{kN}$ ) at bonding temperatures ranging from $150-300^{\circ} \mathrm{C}$ for duration of 15 minutes. An overview of the bonding parameters of the four bonded laminates is given in Table II. The laminates ID have been constructed by numbers and letters having the following meaning: The prefix Au corresponds to the gold bonding and is followed by the bonding temperature $\left({ }^{\circ} \mathrm{C}\right)$.

The applied tool pressure corresponded to a bond pressure of $10 \mathrm{MPa}$. The pressure value is given just as a rough estimate, assuming a perfectly stiff material (rigid body) with parallel surfaces. It should be noted that the actual local pressure can have non- uniformities that are pattern dependent caused by the pressure loading properties of the bonding chuck, pressure diffuser and the silicon wafer. ${ }^{5}$ Additionally, the roughness and waviness of the surfaces will also cause the contact pressure to vary. It is still desirable to make comparisons between the different frame sizes (Table I), for which the difference in the contact pressure of different frames should be considered. We have chosen to roughly estimate the contact pressure of each bonding frame $\left(\sigma_{b}\right)$ by the simple expression.

$$
\sigma_{b}=A_{d}{ }^{*} F_{\text {tool }} / A_{o}{ }^{*} A_{b f}=7.8 / A_{b f}
$$

Here, $F_{\text {tool }}$ is the applied force of the bonding tool $(5 \mathrm{kN}), A_{b f}$ is the nominal bonding area of the particular frame (see Table I), $A_{d}$ is the area of each die $(5200 \times 5200 \mu \mathrm{m})$, and $A_{o}$ is the area of the $\mathrm{Si}$ wafer $\left(0.01745 \mathrm{~m}^{2}\right)$. This contact pressure is what one would have if each die was bonded separately as a rigid body with parallel

Table I. Overview of chip designs.

Frame ID

$20 \mathrm{R}$

40

$40 \mathrm{R}$

$80 \mathrm{R}$

200R

Open
Frame Description

Width $10 \mu \mathrm{m}$, rounded corners

Width $30 \mu \mathrm{m}$, square corners

Width $30 \mu \mathrm{m}$, rounded corners

Width $70 \mu \mathrm{m}$, rounded corners

Width $190 \mu \mathrm{m}$, rounded corners

Width 10, 30, 70 and $190 \mu \mathrm{m}$, opening in bond frame
Number of dies

$\begin{array}{cc}79 & 0.26 \\ 80 & 0.54 \\ 82 & 0.52 \\ 80 & 1.06 \\ 80 & 2.68 \\ 4 & 0.25-2.6\end{array}$


surfaces under a pressure equal to the pressure on the whole wafer. This estimate ignores all horizontal components of stresses and maximizes the difference between the frame sizes. Using these simplifications, the calculated pressure on the $20 \mu \mathrm{m}$ wide frames is $30 \mathrm{MPa}$ and on the $200 \mu \mathrm{m}$ wide frames is $3 \mathrm{MPa}$.

Reliability tests. - The laminates were stored for a minimum of 3 months after bonding and then diced along the diameter into two halves, each here called a half laminate. One half laminate of each laminate ID in Table I was subjected to environmental stress tests consisting of a steady-state life test, a thermal shock test, and a moisture resistance test. The other half was kept as a reference.

The first test was a steady-state life test in which the half laminates were exposed to $150^{\circ} \mathrm{C}$ in an atmospheric ambient for 1000 hours in an oven (Heraeus Instruments). Secondly, the same half laminates were exposed to a thermal shock test where a two chamber system connected with a lift was employed (Heraeus HT7012 S2). The top chamber was maintained at a constant temperature of $+200^{\circ} \mathrm{C}$ and the bottom chamber was maintained at $-65^{\circ} \mathrm{C}$. A dwell time in each chamber of $10 \mathrm{~min}$ and a transition time of $\sim 7 \mathrm{~s}$ were employed. Consecutive exposure to both chambers was considered as 1 cycle and the samples were exposed for 50 cycles. Finally, the same half laminates were exposed to a moisture resistance test where a chamber with controlled humidity and temperature was used (Sunrise E series). A $24 \mathrm{~h}$ initial conditioning of the samples at $80^{\circ} \mathrm{C}$ was done to completely dry out the samples. One complete cycle comprised of 7 steps and the humidity of the chamber was maintained at $90 \%$ for all the steps, as described in MIL-STD-883E. The temperature was varied between $25^{\circ} \mathrm{C}$ to $65^{\circ} \mathrm{C}$ during one cycle. The samples were exposed to 10 cycles. A subcycle of step 7 was performed for 5 of 10 cycles where humidity was uncontrolled and temperature was maintained at $-10^{\circ} \mathrm{C}$ (see MIL-STD-883E).

Characterization. - The amount of inward deflection of bonded membranes was measured by a Zygo NewView 6300 white light interferometer (WLI). The deflection measurements were done on all dies, and were repeated after a period of 3-5 months. The hermetic yield was defined as the percentage of membranes deflecting inwards by more than $2 \mu \mathrm{m}$ after bonding. The open reference dies were left out of the hermetic yield calculation.

MLR was calculated by measuring the deflection of 1-13 membranes at two different times $t_{1}$ and $t_{2}$. Also the deflection of the membranes of the reference dies was measured in order to measure possible deviations from a flat surface. A maximum estimate for the leakage rate could therefore be calculated by the following equation.

$$
\mathrm{MLR}=\Delta P^{*} V / \Delta t
$$

Here, $V$ is the cavity volume $\left(\approx 1.6 \times 10^{-6} 1\right)$, and $\Delta t$ is the time difference [s] between times $t_{1}$ and $t_{2}$. According to Eq. 1, a pressure increase of $72 \mathrm{mbar}$ would result in a deflection decrease of $0.35 \mu \mathrm{m}$. In the calculation, the actual membrane dimensions, $E=165 \mathrm{GPa}$ and $v=0.28$ were used. Hence, if the measured deflection decreased by less than $0.35 \mu \mathrm{m}$, the increase in cavity pressure was lower than 72 mbar.

After environmental stressing, the membranes with inward deflection were identified by visual inspection and compared to a laminate map showing the membranes with inward deflection before environmental stressing. Four months after bonding, the laminates were diced

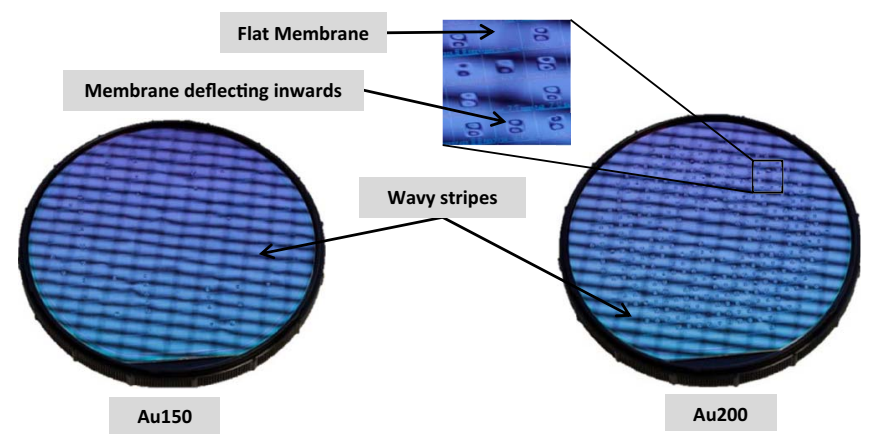

Figure 3. Pictures of bonded laminates Au150 (left) and Au200 (right). Hazy spots on the laminate are the inward deflecting membranes that indicate a good hermetic seal. (The wavy stripes are just a mirror image to emphasize the deflecting membranes.).

into individual dies. Both the half laminates which had been stored and the half laminates which had been subjected to environmental stress were diced. The dicing yield, defined as the percentage of dies that were not delaminated after the dicing process, was recorded.

The dies which survived dicing test were used for subsequent pull tests, measuring the bond strength. 10 dies of F40R frame type was picked from each diced laminate including both their stressed and unstressed halves. The dies were glued to flat headed bolts and pull tested using a MiniMat2000 (Rheometric Inc.). The elongation versus applied force was recorded and the force, at which the fracture occurred, designated as the fracture force, was noted. The bond strength was calculated by dividing the fracture force by the actual bond area.

\section{Results}

Inward membrane deflection of the sealed cavities was observed after bonding. A picture of bonded laminate Au150 and Au200 is shown in Figure 3. The measured actual membrane thickness, inward deflection in membranes and calculated values of $\Delta P$ by Eq. 1 are listed in Table III. The measured deflection values indicate that the laminate $\mathrm{Au} 200$ had the lowest pressure and laminate Au300 had the highest pressure inside the sealed cavity. After a storage period of 3-5 months, an average change of $\sim 0.16 \mu \mathrm{m}$ in membrane deflection of inward deflecting membranes was observed for all laminates with a standard deviation of $0.05 \mu \mathrm{m}$. An estimate for the MLR, calculated from Eq. 3 using a maximum deflection change of $0.35 \mu \mathrm{m}$ (for details see Discussion section), is listed in Table III. The estimated MLR was below $10^{-11} \mathrm{mbar} \cdot 1 \cdot \mathrm{s}^{-1}$ for all laminates. There were no differences in the leak rate estimates for laminates bonded at different bonding temperature. There were also no differences in leak rates between the different frame widths. An average upward deflection of $0.4 \mu \mathrm{m}$ was observed for the intentionally unsealed dies with a standard deviation of $0.2 \mu \mathrm{m}$.

The hermetic yield result of all bonded laminates is shown in Figure 4. Laminate Au250 had the highest hermetic yield with an average of $72 \%$ for all frame types. For the individual frame design F80R, a hermetic yield of $77.5 \%$ was obtained. Laminate Au300 showed an average low hermetic yield of $11 \%$. Studies of pull tested dies showed that the reason of the low yield was misalignment of

Table III. Measured membrane deflections and cavity pressures as calculated from the inward membrane deflections. The maximum leak rate is calculated from corresponding values before environmental stressing.

\begin{tabular}{ccccc} 
Laminate ID & Membrane Thickness $[\mu \mathrm{m}]$ & Measured Deflection $[\mu \mathrm{m}]$ & $\Delta P$ Calculated from Deflection $[\mathrm{mbar}]$ & Max. Leak Rate $\left[\mathrm{mbar} \cdot 1 \cdot \mathrm{s}^{-1}\right]$ \\
\hline Au150 & 42 & - & - & - \\
Au200 & 41.4 & 5.2 & 1118 & $1.4 \times 10^{-11}$ \\
Au250 & 43 & 4.5 & 1087 & $1.4 \times 10^{-11}$ \\
Au300 & 41 & 5.1 & 1057 & $1.4 \times 10^{-11}$
\end{tabular}




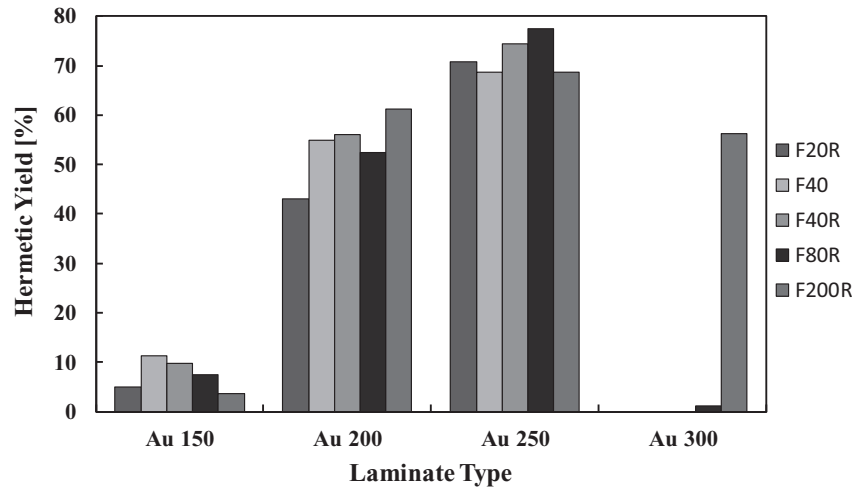

Figure 4. Hermetic yield of 401 dies from all four bonded laminates before environmental tests. Laminates were bonded for 15 minutes applying 2266 mbar tool pressure at different temperatures ranging from $150-300^{\circ} \mathrm{C}$. The reason for the low yield of all but the widest frames for Au300 is misalignment.

the wafers. The widest frame design $(200 \mu \mathrm{m})$ on laminate Au300 had $56 \%$ yield, while frames of width 20 and $40 \mu \mathrm{m}$ had $0 \%$ yield. Laminate Au150 had an average low hermetic yield of 7\%, without any clear evidence of misalignment.

No membranes which were originally deflecting inwards after bonding had turned flat on any of the dies after exposure to $150^{\circ} \mathrm{C}$ for $1000 \mathrm{~h}$ during steady-state life test. All laminates also survived the thermal shock test and moisture resistance test, showing no new flat membranes. Even laminate Au150 which had a low hermetic yield, had no changes in the number of deflecting dies caused by the environmental tests. There was no measurable effect of moisture or the exposure to sudden temperature variations on the hermeticity of the Au bonds.

The dicing yield results of stressed and un-stressed laminate halves are shown in Figures 5 and 6. The dicing yield of laminates Au150, Au200 and Au250 was above 97\%, regardless of frame type. This shows that these laminates had bonds strong enough to survive the force exerted by the dicing saw during the dicing process. No significant effect of different frame width or geometry was observed on the dicing yield of these three laminates. For the half stressed laminate Au300, a dicing yield of 36\% for frame F20R was observed. This dicing yield was significantly lower than the $88 \%$ dicing yield obtained for the wider frame widths.

Figure 7 shows the mean bond strength results of the pull tested dies from all stressed and unstressed half laminates. The mean bond strength of unstressed laminates ranged from 51-175 $\mathrm{MPa}$, while mean bond strength of stressed laminates ranged from 44-156 MPa. When increasing the bonding temperature from $150^{\circ} \mathrm{C}$ to $200^{\circ} \mathrm{C}$, the bond strength increased by more than $70 \mathrm{MPa}$ for both unstressed and stressed laminates. When further increasing the bonding temperature

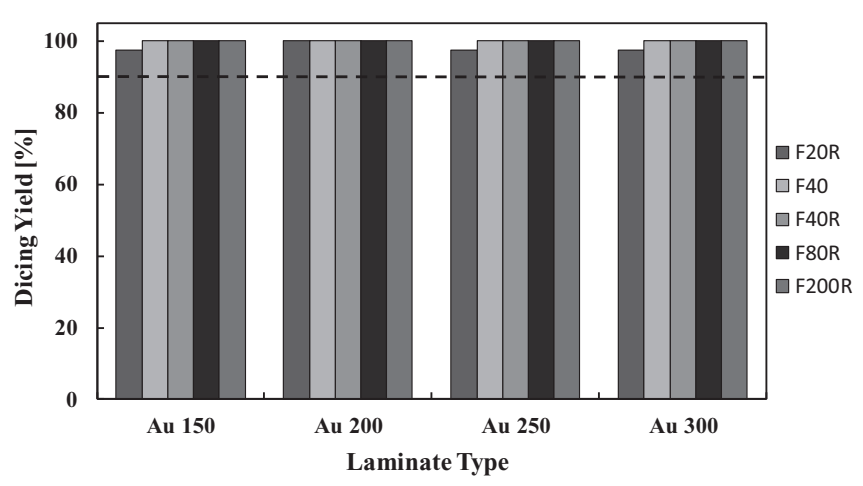

Figure 5. Dicing yield of unstressed half laminates for all laminates and bond frame designs.

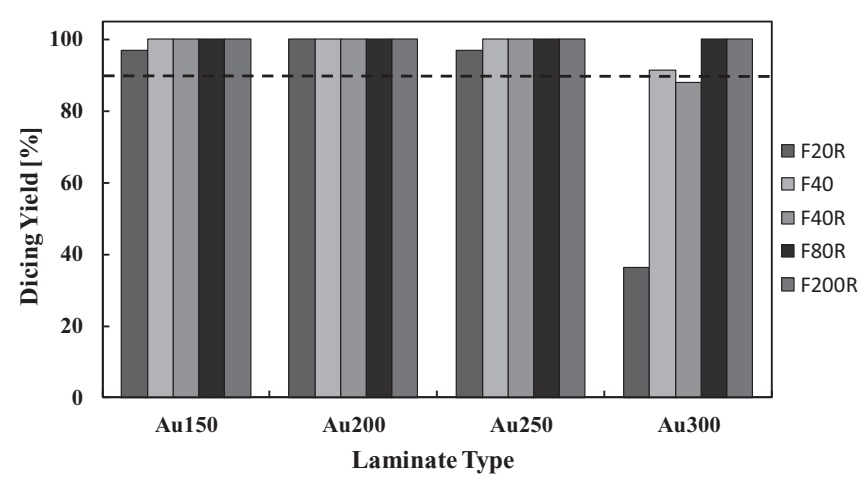

Figure 6. Dicing yield of stressed half laminates for all laminates and bond frame designs.

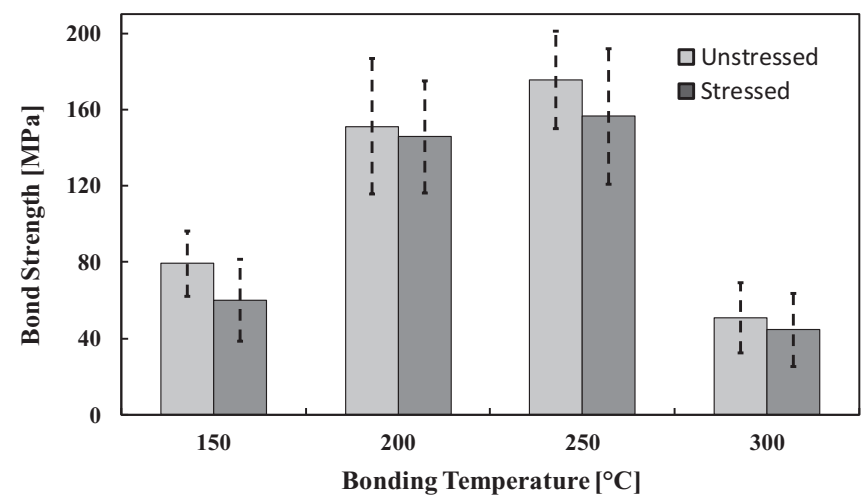

Figure 7. Mean bond strength and standard deviation of frame F40R for all stressed and unstressed half laminates, calculated for minimum 6 dies.

from $250^{\circ} \mathrm{C}$ to $300^{\circ} \mathrm{C}$, the bond strength decreased by more than $110 \mathrm{MPa}$ for both unstressed and stressed laminates. No significant difference in bond strength between stressed and unstressed dies was observed for dies from any of the laminates.

The results of pull tested dies of all frame types from stressed half laminate Au200 are shown in Figure 8. Frame F20R had the lowest average fracture force of $37 \mathrm{~N}$. Frames F40, F40R and F80R and F200R had no significant difference in their fracture force; all had an average fracture force between $65-75 \mathrm{~N}$. Bond frame F200R had the lowest average bond strength of $10 \mathrm{MPa}$. Frames F20R, F40 and F40R had no significant difference in their bond strength; all had average bond strengths above $139 \mathrm{MPa}$.

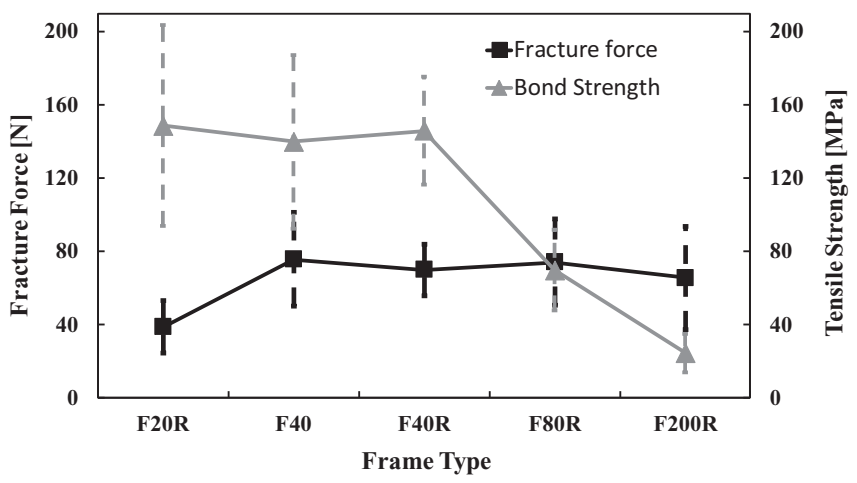

Figure 8. Mean fracture force, mean tensile strength and their standard deviation from five different frame types of stressed half laminate Au200. The results were calculated for minimum 8 dies. The mean tensile strength and its standard deviation are calculated by dividing the fracture force by the frame area. 


\section{Discussion}

As mentioned in the Results section, laminate Au300 was found to be misaligned. Hence, the reason of laminate Au300 showing low average hermetic yield and bond strength can be the misalignment of the laminate. Also a significant decrease in dicing yield of frame F20R was observed for laminate Au300 after environmental stressing. The low dicing yield of the stressed F20R frame may also have been due of its low tolerance to misalignment as it is narrower than the other frame types. Since the results obtained for the misaligned laminate Au300 are uncertain, they will not be further discussed in this section.

As seen in Figures 4 and 7, there was an increase of 46 percentage points in mean hermetic yield and an increase of $72 \mathrm{MPa}$ in bond strength when increasing the bonding temperature from 150 to $200^{\circ} \mathrm{C}$. While there was only an increase of 18 percentage points in mean hermetic yield and an increase of $24 \mathrm{MPa}$ in bond strength when increasing the bonding temperature from 200 to $250^{\circ} \mathrm{C}$. The increase in bond strength with increasing bonding temperature is caused by the increased diffusion of $\mathrm{Au}$ atoms with increasing temperature. The diffusion is controlled by an Arrhenius relationship with an exponential dependence on temperature. ${ }^{15}$ In our understanding, bonding between two $\mathrm{Au}$ surfaces occurs at initial contact points where the two Au surfaces are in direct contact. The number and area of these initial contact points are affected by the roughness of the two Au surfaces and by the applied bonding pressure. At the initial contact points, $\mathrm{Au}$ atoms can diffuse at the initial bonding interface, and grain growth and bonding can take place. The deformation of $\mathrm{Au}$, creep and diffusion may also cause the contact points to increase in size, so that the bonded area expands. The maximum area that can be bonded is the area where the two Au surfaces overlap. Therefore, due to the diffusion dependency on temperature it is likely that the overlapping $\mathrm{Au}$ area that has been bonded is larger for higher temperatures. This could explain the increase in bond strength with increasing bonding temperature. The small difference in bond strength as the temperature was increased from $200^{\circ} \mathrm{C}$ to $250^{\circ} \mathrm{C}$ could indicate that the contact area between the bonding surfaces at 200 and $250^{\circ} \mathrm{C}$ was almost the same. The bonding temperatures used in our work for providing hermetic seals are lower than the previously reported temperatures of 320 and $400^{\circ} \mathrm{C}$ by Park et al. ${ }^{12}$ and $\mathrm{Xu}$ et al. ${ }^{13}$ Our results indicate that a lower limit of bonding temperature resulting in hermetic sealing is between 150 and $200^{\circ} \mathrm{C}$ for $\mathrm{Au}$ - $\mathrm{Au}$ thermocompression bonding for sputter deposited films applying a tool pressure of 2.3 bar. Also, the mean bond strengths obtained from our laminates was higher than the previously reported bond strength of $\sim 20 \mathrm{MPa}$ by Kurotaki et al. ${ }^{4}$ and $\sim 10 \mathrm{MPa}$ by Taklo et al. ${ }^{8}$

Table III shows that the calculated maximum leak rate of the bonded dies was below $10^{-11} \mathrm{mbar} \cdot 1 \cdot \mathrm{s}^{-1}$ for all laminates. The actual leak rate of the bonds may be significantly lower than the calculated $10^{-11} \mathrm{mbar} \cdot 1 \cdot \mathrm{s}^{-1}$ range; however the accuracy of the applied detection method prevented a better estimate. A leak in a die can be related to the pressure increasing within the sealed cavity over time. Considering uncertainties caused by the membrane thickness, the WLI scan position, and the atmospheric pressure, the maximum change in membrane deflection was over-estimated to $0.35 \mu \mathrm{m}$. The maximum deflection change of $0.35 \mu \mathrm{m}$ was taken due to the following assumptions: a change in atmospheric pressure by 29 mbar would correspond to a change in membrane deflection by $0.14 \mu \mathrm{m}$, an error of $25 \mu \mathrm{m}$ in measuring the same spot by WLI will correspond to a change in deflection by $0.05 \mu \mathrm{m}$ and $0.16 \mu \mathrm{m}$ was the measured change in deflection. In our work, the change in the deflection of the membranes was used only to monitor significant changes in pressure inside the sealed cavity. However, measured reductions in deflection could be related to possible (theoretical) leak rates. Our maximum estimated leak rates are factors 10 (Park et al. ${ }^{12}$ ) and $100\left(\mathrm{Xu}\right.$ et al. $\left.{ }^{13}\right)$ lower than the previously published results. Leak rates between $10^{-11}$ and $10^{-16} \mathrm{mbar} \cdot 1 \cdot \mathrm{s}^{-1}$ are needed for various industrial applications. ${ }^{16}$ Our results indicate that $\mathrm{Au}-\mathrm{Au}$ thermocompression bonds can meet requirements in this range.
The dicing yield above $90 \%$ of laminate Au150 suggests that even a bonding temperature of $150^{\circ} \mathrm{C}$ was sufficient to obtain a bond strong enough to survive the force exerted by the dicing saw. Even though laminate Au150 had low hermetic yield, the high dicing yield and mean bond strength above $59 \mathrm{MPa}$ indicates that there were enough contact points between the opposing $\mathrm{Au}$ surfaces to make the bond strong, but not hermetic. There was no significant difference in dicing yield and bond strength between any of the laminates after environmental stressing (except the misaligned Au300). This suggests that the bonds were resistant to the environmental conditions encountered during the reliability tests. Deterioration of the bonds after environmental tests was observed by Malik et al. in case of Al-Al bonding. ${ }^{17}$ It seems that unlike $\mathrm{Al}, \mathrm{Au}$ is a sealing material that does not deteriorate during the applied environmental tests, may be due to its noble nature.

As seen in Figure 8, the fracture force was similar for frames of width $40 \mu \mathrm{m}$ and wider. This implies that the bond strength will decrease with increasing frame width, since bond strength is calculated by dividing fracture force by the area of the frame. When the fracture force is not dependent on the area, the bond strength parameter will still depend on the area. It seems likely that fracture force cannot increase with increase in frame width; therefore selecting a frame width of $40-80 \mu \mathrm{m}$ over $200 \mu \mathrm{m}$ seems a good choice for reducing the die area.

\section{Conclusions}

The strength, hermeticity and reliability of wafer-level Au-Au thermocompression bonds realized at temperatures $150-300^{\circ} \mathrm{C}$ were investigated in this paper. The results show that a bonding temperature higher than $150^{\circ} \mathrm{C}$ is required to produce laminates with a high hermetic yield when the applied bond tool pressure is 2266 mbar and the bonding time is 15 minutes. Laminates bonded at or above $200^{\circ} \mathrm{C}$ had high hermetic yield and bond strength above $24 \mathrm{MPa}$. Unstressed laminates had a dicing yield above $97 \%$ and bond strength of $79 \mathrm{MPa}$, even at bonding temperature of $150^{\circ} \mathrm{C}$. No deterioration of hermeticity was observed in any of the laminates following environmental stressing consisting of steady-state life test, thermal shock test and moisture resistance test. The fracture force was not dependent on the frame width. Frame F20R showed the lowest fracture force, while frames F40, F40R, F80R and F200R had fracture force between 65-75 N. The estimated maximum leak rate for all bonded laminates was below $10^{-11} \mathrm{mbar} \cdot 1 \cdot \mathrm{s}^{-1}$.

\section{Acknowledgments}

This work was supported by the Research Council of Norway through the MSENS project, contract No 210601/O30, and NorFab - the Norwegian infrastructure for micro- and nanofabrication. The authors thank the members of the IMST group at HBV for their support and Astrid-Sofie Vardøy from SINTEF ICT for her extended help during reliability tests.

\section{References}

1. M. Esashi, J. Micromech. Microeng., 18, 073001 (2008).

2. S. Farrens, Proc. Mater. Res. Soc. Symp, 1112-E01 (2008).

3. R. Fraux and J. Baron, 3D packaging, 21, 24 (2011).

4. C. S. Tan, J. Fan, D. F. Lim, G. Y. Chong, and K. H. Li, J. Micromech. Microeng., 21 075006 (2011).

5. C. H. Tsau, S. M. Spearing, and M. A. Schmidt, J. Microelectromech. Syst., 13, 6 (2004).

6. M. M. V. Taklo, P. Storås, K. Schjølberg-Henriksen, H. K. Hasting, and H. Jakobsen, J. Micromech. Microeng., 14, 884 (2004).

7. H. R. Tofteberg, K. Schjølberg-Henriksen, E. J. Fasting, A. S. Moen, M. M. V. Taklo, E. U. Poppe, and C. J. Simensen, J. Micromech. Microeng., 24, 084002 (2014).

8. H. Kurotaki, H. Shinohara, H. Kobayashi, J. Mizuno, and S. Shoji, Proc MicroNano, June 3-5, Kowloon, Hong Kong, pp. 747 (2008).

9. W-S. Wang, Y-C. Lin, M. Esashi, and T. Gessner, Proc WaferBond'13, Dec. 5-6, Stockholm, Sweden, pp. 89 (2013).

10. Y. Tao and A. P. Malshe, Microelectron. Reliab., 45, 559 (2005).

11. S. Millar and M. P. Y. Desmulliez, Sensor Review., 29, 4 (2009). 
12. G. S. Park, Y. K. Kim, K. K. Paek, J. S. Kim, J. H. Lee, and B. K. Ju, Electrochem Solid St, 8, 12 (2005).

13. D. Xu, E. Jing, B. Xiong, and Y. Wang, IEEE Trans Adv. Pack., 33, 4 (2010).

14. W. K. Schomburg, Introduction to Microsystem Design, Springer, Berlin, Heidelberg (2011)
15. B. Okkerse, Phys. Rev., 103, 1246 (1956).

16. S. Costello and M. P. Y. Desmulliez, in Hermeticity Testing of MEMS and Microelectronic Packages, p. 63, ArtechHouse, Norwood, Massachusetts (2013).

17. N. Malik, E. Poppe, K. Schjølberg-Henriksen, M. M. V. Taklo, and T. G. Finstad, ECS Trans., 64, 5 (2014). 